\title{
A SIMPLIFIED METHOD FOR ESTABLISHING SAFE AVAILABLE EVACUATION TIME BASED ON A DESCENDING SMOKE LAYER
}

\begin{abstract}
Keeping the smoke layer at a safe height is one of the most important tenability criteria in assessment of evacuation from buildings. The basis of this approach is an accurate approximation of the fire and smoke plume, which is formed above the fire source. The major variables affecting smoke filling are the fire growth rate and enclosure geometry, i.e. the floor area and height. This paper deals with the implementation of a new method for establishing safe available evacuation time based on the fundamental principles of smoke generation and flow into the national fire safety design standards in the Czech and Slovak Republic. Some of these calculation methods have also been included in fire safety engineering ISO standards. The devised method is based on the t-squared fire growth model and correlations for smoke production and air entrainment into the rising plume of smoke. Subsequently, the proposed method is validated against a wide range of benchmark scenarios in the two-zone fire model CFAST. The paper compares the differences, comments on their causes and evaluates the applicability of the new method in both countries. The proposed method is not only compatible with the national fire safety design standards, but also allows for a more precise assessment of life safety without the need for overly complicated calculations.
\end{abstract}

Keywords: available safe evacuation time (ASET), $t^{2}$-fire, CFAST, smoke layer

\section{Introduction}

One of the most important requirements of buildings, from a fire safety point of view, is to ensure safe evacuation of occupants. Safe evacuation is usually established by the comparison of the required safe evacuation time (RSET) and the available safe evacuation time (ASET) [1], [2], [3], [4], [5]. Safe evacuation conditions and sufficient evacuation time are particularly important in cases with challenging conditions such as high-rise buildings, assembly spaces, occupants with impairments, etc. [6].

The primary factor affecting the ASET is the threat resulting from the descending layer of smoke in an enclosure or the availability of a smoke-free clear layer at low level. The clear layer in an enclosure is considered safe until the smoke layer descends to $2.5 \mathrm{~m}$ above the floor, i.e. the smoke-free layer is $2.5 \mathrm{~m}$ high and smoke is above the heads of the occupants. The clear layer height criterion depends on the type of occupancy within the building; for example, in public buildings it is $3 \mathrm{~m}$ above the floor and in car parks $80 \%$ of their total clear height. Given the average construction and clear height of a storey, $2.5 \mathrm{~m}$ may be considered as a representative value for typical situations [7].
A number of methods have been derived for the determination of smoke filling and layer descent in an enclosure (e.g. [7], [8], [9]). The methods derived by foreign authors employ variables, which the standardised design calculation in the Czech Republic and Slovak Republic usually do not utilize (e.g. fire growth coefficient). This limits the applicability of the smoke calculation methods in the national fire safety design frameworks.

The aim of this paper is to present a set of modified equations from ISO 16735 [8] for the descending smoke layer, which have been derived so that they utilize the variables contained in the fire safety design standards in the Czech Republic and Slovak Republic. A comparison with the CFAST zone computer fire model was carried out to evaluate the validity and applicability of the derived equations.

\section{Smoke spread in an enclosure}

Fire growth is usually represented by a localised fire, which is a fire on a limited area, resulting in burning of a limited amount of fuel (fire load) [10]. One of the characteristic accompanying phenomenon is the formation of a vertical plume of combustion

\footnotetext{
* ${ }^{1}$ Jiri Pokorny, ${ }^{2}$ Vladimir Mozer, ${ }^{1}$ Lenka Malerova, ${ }^{3}$ Dagmar Dlouha, ${ }^{4}$ Peter Wilkinson

${ }^{1}$ Department of Civil Protection, Faculty of Safety Engineeing, VSB - Technical University of Ostrava, Czech Republic

${ }^{2}$ Department of Fire Engineering, Faculty of Security Engineering, University of Zilina, Slovakia

${ }^{3}$ Department of Mathematics and Descriptive Geometry, VSB - Technical University of Ostrava, Czech Republic

${ }^{4}$ Pyrology Limited, Harborough Innovation Centre, Market Harborough, Leicestershire, United Kingdom

Email: jiri.pokorny@vsb.cz
} 


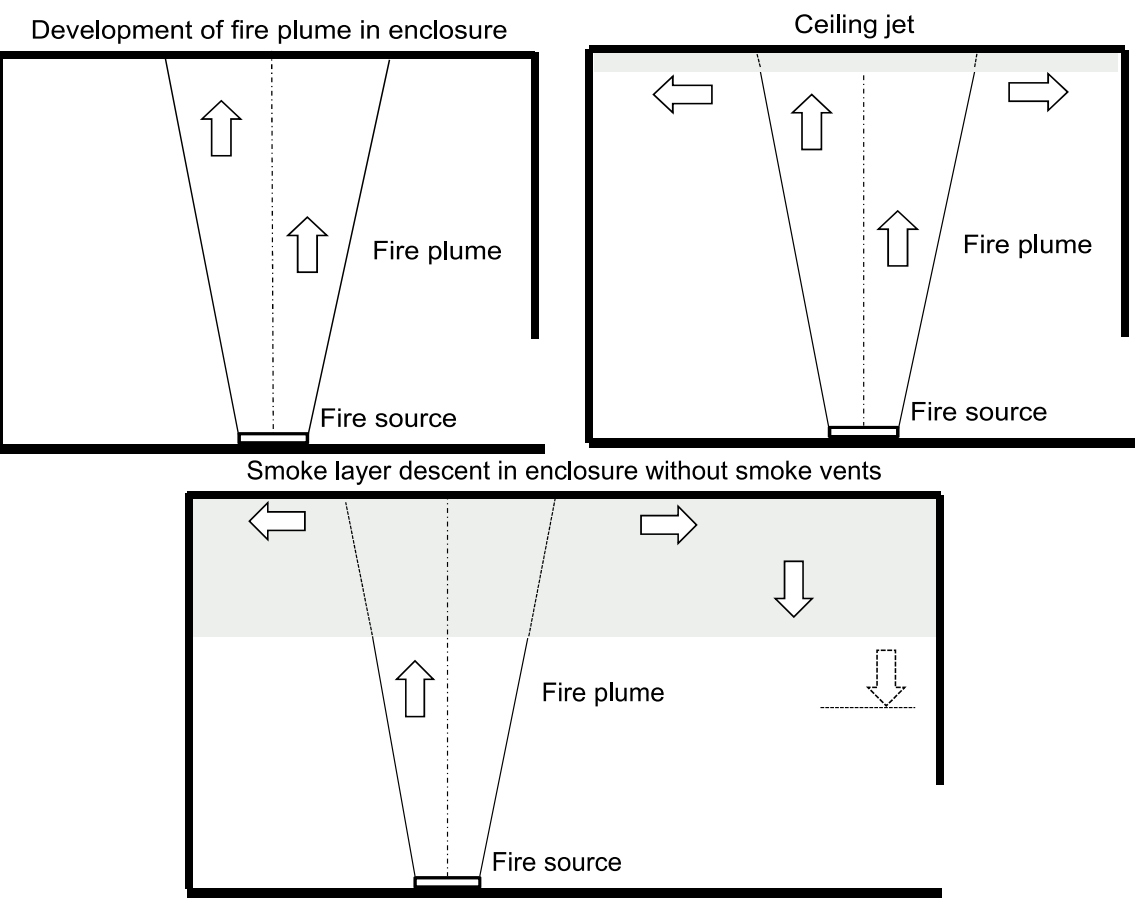

Figure 1 Schematic depiction of enclosure smoke filling (adapted from [13])

products (fire plume). The fire plume is a representation of mass and energy transport from the fire into the enclosure.

With the progressing fire growth, the temperature of smoky gases (combustion products) raises, resulting in increased buoyancy. When the temperature difference is sufficient the fire plume reaches the ceiling of the enclosure and a ceiling jet (radial smoke spread) is formed.

Smoky gases spread radially under the ceiling in a relatively thin layer from the plume centreline until they reach the enclosure bounding constructions. Once the radially spreading thin smoke layer reaches the enclosure boundaries the layer starts descending. This is known as smoke filling, when more hot smoky gases enter the layer through the plume, thereby increasing its volume and temperature. Due to the decrease of the smoke layer height, the distance between the fire source and the bottom of the layer is reduced, resulting in less ambient air entraining into the plume and a further increase in smoke layer temperature [1], [11], [12]. The layer descends until it fills the enclosure completely or reaches an opening with sufficient discharge capacity.

The process of smoke filling in an enclosure is shown in Figure 1.

\section{Methodology}

National and international technical standards play an important role in building quality and fire safety design [14]. One of the possibilities for the determination of smoke filling in enclosures without smoke management measures, is described in the fire safety engineering standards from International Organization for Standardization (ISO) [8]:

$z=\left(\frac{0.076}{\rho_{s}} \frac{(1-\chi)^{1 / 3} \cdot \alpha^{1 / 3}}{A} \frac{2}{n+3} t^{\left(1+\frac{n}{3}\right)}+\frac{1}{H^{2 / 3}}\right)^{-3 / 2}$

where

$z \quad$ Interface height above the base of fire source $(\mathrm{m})$

$\chi$ Fraction of heat released that is emitted as thermal radiation $(-)$

$\alpha \quad$ Fire growth rate $\left(\mathrm{kW} . \mathrm{s}^{-2}\right)$

$\rho_{\mathrm{s}} \quad$ Smoke density $\left(\mathrm{kg} \cdot \mathrm{m}^{-3}\right)$

A Floor area of enclosure $\left(\mathrm{m}^{2}\right)$

n $n$-th power (-)

$H$ Height of enclosure (m).

Equation (1) provides valid results only in case that the distance between the fire and the bottom of the smoke layer is greater than the average flame height [7].

Fire dynamics in Equation (1) is taken into account through the fire growth rate $\alpha$, i.e. the equation describes a fire that grows with time. The fire growth rate $\alpha$, however, does not have a direct connection to the national fire safety design standards in the Czech Republic and Slovak Republic.

Analytical work, analysing the localised fire was, undertaken during 2016 and 2017. Possible connections between the fire growth rate $\alpha$ and selected design values describing fire growth in national standards were analysed. As a result the following equation was derived to calculate the fire growth rate $\alpha$, using the national design parameters [13]: 
Table 1 Input variables for model cases

\begin{tabular}{ccccc}
\hline Type of use & CSN & Variable fire load & Fixed fire load & Coefficient \\
& 730802 & $\mathrm{p}_{\mathrm{n}}\left(\mathrm{kg} \cdot \mathrm{m}^{-2}\right)$ & $\mathrm{p}_{\mathrm{s}}\left(\mathrm{kg} \cdot \mathrm{m}^{-2}\right)$ & $\mathrm{a}_{\mathrm{n}}(-)$ \\
Annex A & item 5.1 & 15 & 6.2 & 0.8 \\
Sport hall & item 6.2 .5 & 90 & 6.2 & 0.9 \\
Shopping centre & & & 0.9 \\
\hline
\end{tabular}

$\alpha=\frac{a^{2} \cdot p}{2560}$

where

a fire growth rate coefficient (-)

$p$ fire load $\left(\mathrm{kg} \cdot \mathrm{m}^{-2}\right)$.

Equations for the determination of the time for smoke layer descent to $2.5 \mathrm{~m}$ above floor level in non-industrial and industrial occupancies were derived by substituting Equation (2) into Equation (1) and subsequent mathematical adjustments.

The time for smoke layer descent to $2.5 \mathrm{~m}$ above the floor level in non-industrial occupancies can be determined by the following equation:

$t=\left(114 \cdot 10^{6} \frac{A^{3}}{a^{2} \cdot p} \cdot\left(0.543-H^{-\frac{2}{3}}\right)^{3}\right)^{\frac{1}{5}}$

where

$t$ time for smoke layer descent to $2.5 \mathrm{~m}$ above floor level (s).

The time for smoke layer descent to $2.5 \mathrm{~m}$ above floor level in industrial occupancies can be determined by the following equation:

$t=\left(114 \cdot 10^{6} \frac{A^{3}}{\bar{p}} \cdot\left(0.543-H^{-\frac{2}{3}}\right)^{3}\right)^{\frac{1}{5}}$

where

$\bar{p}$ average fuel load $\left(\mathrm{kg} \cdot \mathrm{m}^{-2}\right)$.

Further details regarding the determination of fuel load $p$, fire growth rate coefficient $a$, and average fuel load $\bar{p}$ may be found in [15], [16].

\section{Model description}

A set of rectangular-geometry compartments of varying area and height was modelled in CFAST, a zone computer model.

\subsection{Consolidated Model of Fire and Smoke Transport (CFAST)}

CFAST is a two-zone fire model used to calculate the evolving distribution of smoke, fire gases and temperature throughout compartments of a building during a fire. These can range from very small containment vessels, of the order of $1 \mathrm{~m}^{3}$ to large spaces of the order of $1000 \mathrm{~m}^{3}$, [17], [18]
The modelling equations used in CFAST take the mathematical form of an initial value problem for a system of ordinary differential equations (ODEs). These equations are derived using the conservation of mass, the conservation of energy (equivalent to the first law of thermodynamics), the ideal gas law and relations for density and internal energy. These equations predict as functions of time quantities such as pressure, layer height and temperatures given the accumulation of mass and enthalpy in the two layers. The CFAST model then consists of a set of ODEs to compute the environment in each compartment and a collection of algorithms to compute the mass and enthalpy source terms required by the ODEs, [17], [18].

The zone fire model is considered as an adequate tool for the assessment of accuracy of the derived equations in relation to the spatial descent of smoke layer, since local deviations are not significant in general ASET determination. In addition, CFAST was used within the limits stated in the accompanying documentation [17], [18] and the cases modelled were simple smoke-filling scenarios without complex flows and geometry. It is therefore reasonable to accept the results as generally valid for the purposes of this research.

\subsection{Compartment geometry and ventilation}

The derived equations were evaluated against the results from the CFAST zone computer fire model in two model cases. The first one was a sports hall with a low variable fire load and slow fire growth rate coefficient (lower $a_{\mathrm{n}}$ ) and the second one was a shopping centre with a significantly greater variable fire load and fire growth rate coefficient (greater $a_{\mathrm{n}}$ ). The base input parameters are listed in Table 1.

In both model cases the floor area was varied from 100 up to $2500 \mathrm{~m}^{2}$ and the clear height from 3 up to $12 \mathrm{~m}$.

There were no ventilation openings assumed in the enclosure apart from an opening ( $1 \mathrm{~m}$ wide and $2 \mathrm{~m}$ high) at the floor level to allow free air circulation and avoid pressure build-up in the enclosure. This opening had no effect on the smoke layer itself as its soffit was below the critical smoke layer height of $2.5 \mathrm{~m}$.

\subsection{Fire scenarios and fuel properties}

Fires are usually described by a time-temperature relation or heat release rate. The basic assumption employed in this study 


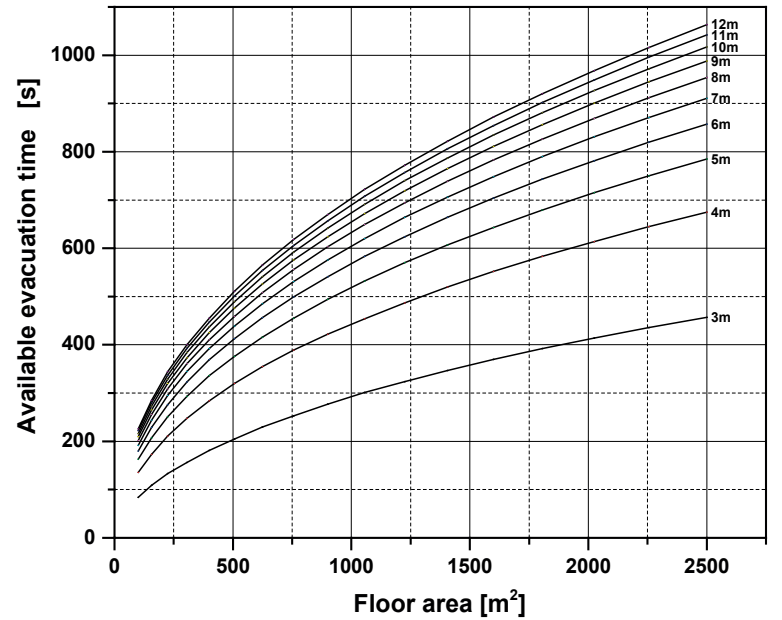

a) CFAST simulation results

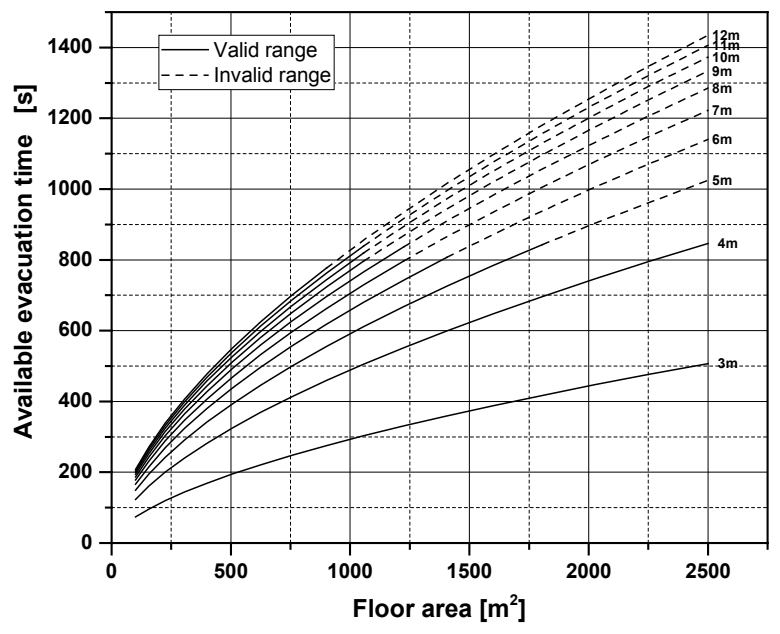

c) ISO Equation (1) - no flame height criterion

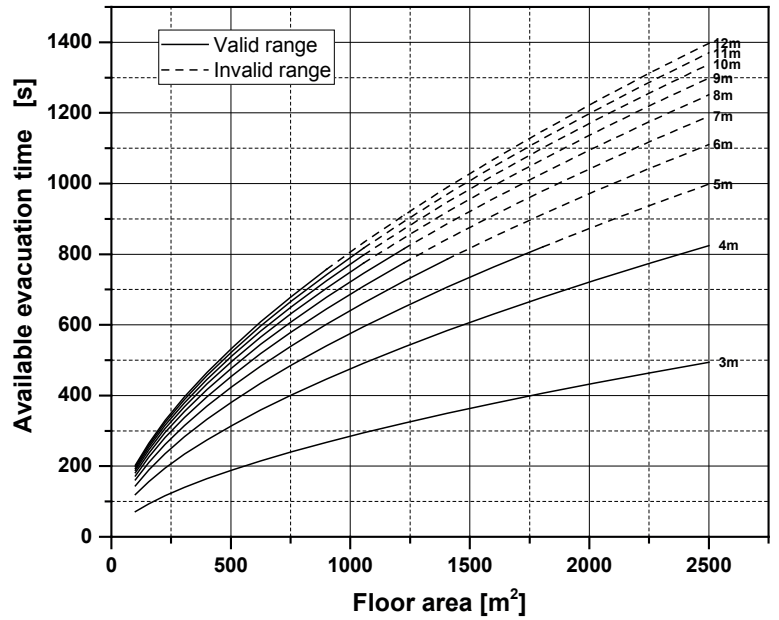

b) Modified ISO Equation (3)

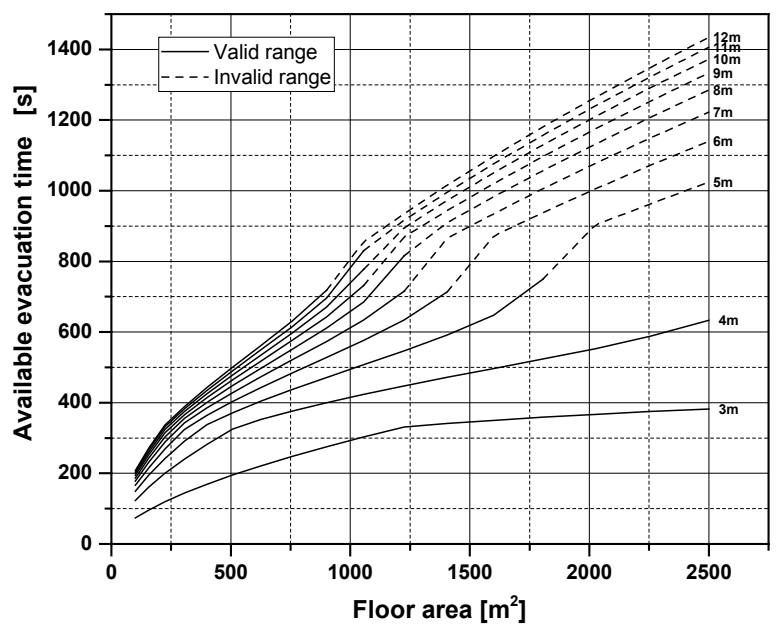

d) ISO Equation (1) - with flame height criterion

Figure 2 Available safe evacuation time for the sports hall model (each curve represents a different enclosure height)

is that only the growth phase of a fire is considered relevant to evacuation. The tenability limits are far exceeded by the time the fire reaches flashover, therefore, it is not necessary to consider the phase of fully developed fire when evaluating the safe available evacuation time in the room of fire origin.

During the growth phase, the fire is fuel-bed controlled (well ventilated) and its heat output grows with time. For this purpose the $t^{2}$ - fire model was used in this paper to prescribe the development of the heat release rate (HRR) with time. This model is well established widely used in the fire safety engineering field, see e.g. [19], [20]. Based on the previous work [13] and in relation to the standards [15], [16], a modified version of this equation was employed:

$Q=\frac{p \cdot a^{2} \cdot t^{2}}{2560}$ where

$Q$ Heat release rate $(\mathrm{kW})$.

Since the incubation time - the period from ignition to sustained growth - is rather variable, ranging from 0 to 100's of seconds, it was not included in the simulation. The HRR grows from $t=0 \mathrm{~s}$ without any delay. Once again, this errs on the side of safety and allows for a wide application of the obtained results.

It is not necessary to consider the detailed fuel composition and combustion chemistry, see for example [21], since the cut-off criterion (the smoke layer $2.5 \mathrm{~m}$ above floor level) is set such that no occupant exposure is expected. This allows for a more general application of results, which are primarily dependent on the geometry of the enclosure and the heat output of the fire.

The fire burning duration in all simulated cases was set to $600 \mathrm{~s}$ 


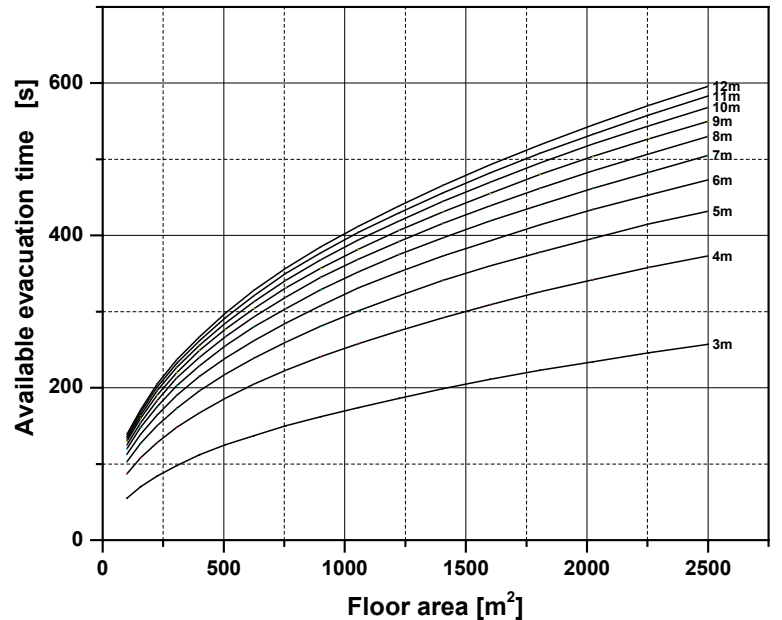

a) CFAST simulation results

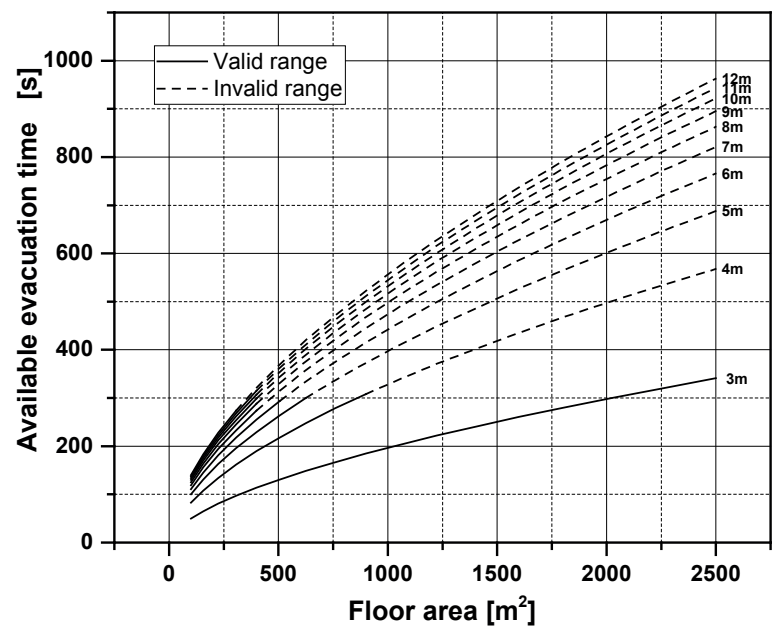

c) ISO Equation (1) - no flame height criterion

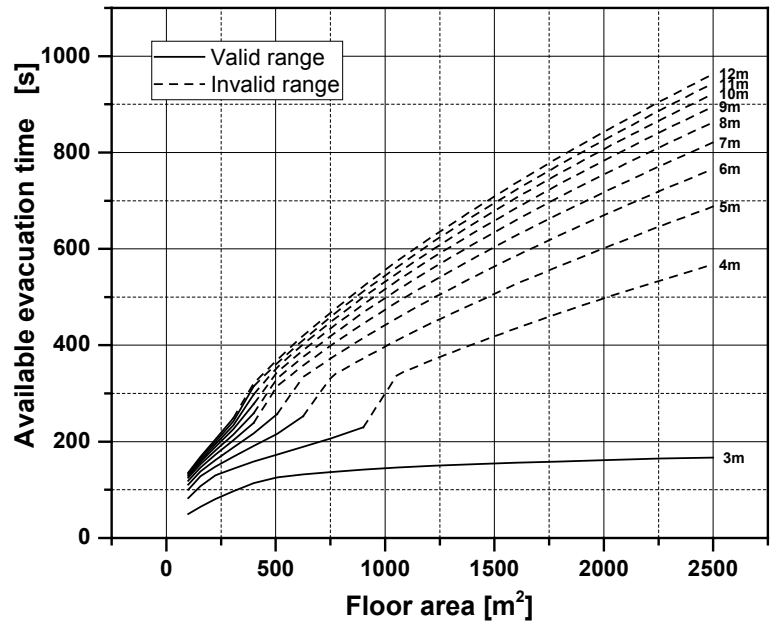

b) Modified ISO Equation (3)

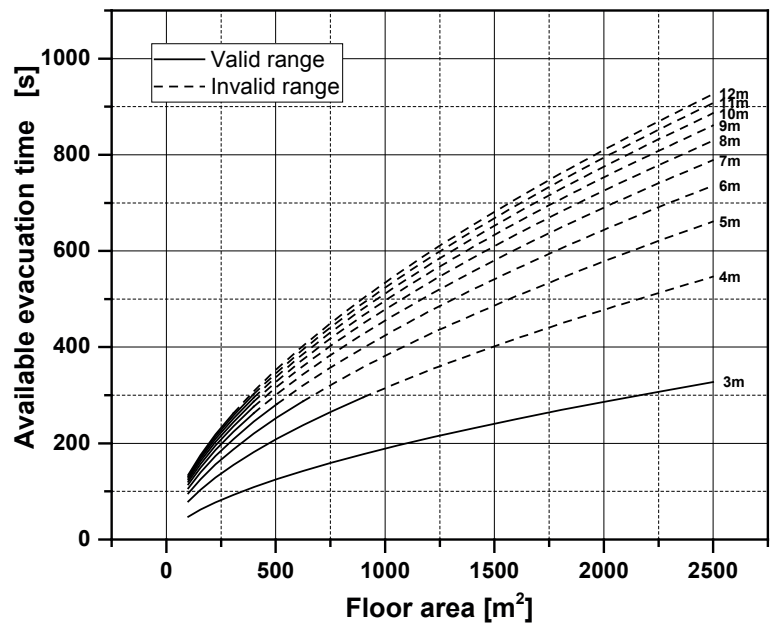

d) ISO Equation (1) - with flame height criterion

Figure 3 Available safe evacuation time for the shopping centre model (each curve represents a different enclosure height)

\subsection{Tenability criteria}

The decrease of the smoke layer height to $2.5 \mathrm{~m}$ above the floor was considered as the tenability cut-off criterion. The time of smoke layer descent to this height was considered as the available safe evacuation time.

\section{Results}

For each of the evaluated building use types, i.e. a sports hall (Figure 2) and a shopping centre (Figure 3), a series of graphs were produced, showing the dependency of the ASET on the enclosure floor area and height, in relation to the calculation approach employed. The CFAST simulation results were considered as benchmark to which the other calculation approaches were compared.
The $\mathrm{x}$-axes of the graphs represent the variable floor area and $y$-axes the available safe evacuation time, i.e. the time in which the smoke layer descended to $2.5 \mathrm{~m}$ above the floor level and each curve in the series represents a different clear height of the enclosure.

The curves resulting from the application of Equation (1) and Equation (3) are shown partially in solid and partially in dashed line. The continuous line indicates the range in which the average flame height is lower than the smoke layer height, i.e. the range in which the equations are valid. The dashed line indicates the range in which the average flame height exceeds the smoke layer height, i.e. the range in which the equations are invalid.

The differences between the results from equations described above and the benchmark CFAST simulations were summarised in Table 2. The differences within the valid and invalid ranges are indicated for comparison. 
Table 2 Differences between simulation and calculation results

\begin{tabular}{ccccc}
\hline Type of use & \multicolumn{3}{c}{ Average difference from simulation results (\%) } \\
\cline { 2 - 6 } & & Equation (1) & & Equation (3) \\
& Valid range & Invalid range & Valid range & Invalid range \\
\hline Sports hall & 9 & 22.6 & 8.1 & 19.9 \\
Shopping centre & 11.6 & 38.7 & 8.7 & 33.8 \\
\hline
\end{tabular}

It is expected that similar differences in results would be obtained when using Equation (4) for industrial buildings due to the significance of the flame height.

\section{Discussion}

The developed method (derived Equation (3) and Equation (4)) for determination of the available safe evacuation time (ASET) was based on the descending smoke layer in an enclosure without smoke ventilation openings. It was validated against two model cases: a sports hall and a shopping centre. These building use types represent two ends of the spectrum from the variable fire load $(p)$ and the burning rate coefficient $(a)$ points of view (high and low values characterising the fire dynamics). These variables also represent important input for the application of the devised method.

The selected geometry parameters of the model cases, the floor areas $100-2500 \mathrm{~m}^{2}$ and heights $3-12 \mathrm{~m}$, cover a significant range of the enclosures in real buildings of these types. The maximal floor area of the evaluated enclosures also corresponds with the standard spatial limits of smoke sections used in smoke management system design [7].

Equation (5) was used to establish the heat output of the design fires, which creates a connection to the input values used in building fire safety design in the Czech Republic and Slovak Republic.

The results of the modelled cases are shown in Figure 2 and Figure 3 and the average differences (in \%), resulting from the comparison of the application of Equation (1) and Equation (3) and the zone fire model CFAST, are listed in Table 2. The differences were established for the range in which the average flame height is lower than the smoke layer height, i.e. the range in which the equations are valid, as well as the range in which the average flame height exceeds the smoke layer height, i.e. the range in which the equations are invalid.

As expected there is a strong dependence of the equation validity range on the fire growth rate expressed through Equation (2). Since the height of the flame is proportional to the heat output of the fire, the slower the fire growth is the greater the range in which Equations (3) and (4) remain valid. Overall, for the valid range for Equation (3) are as follows:

- sports hall (lower fire growth rate) - equation is valid for ASET values below 800 seconds;
- shopping centre (greater fire growth rate) - equation is valid for ASET values below 300 seconds.

The above validity limits are relevant for the entire range of enclosure floor areas and heights evaluated. This may appear contradictory with regard to the enclosure height. However, a greater height results in a greater air entrainment, resulting in a greater volume of smoky gases filling the smoke reservoir.

The above is also confirmed by the results from Table 2, which states differences for the modified ISO Equation (3) of $8.1 \%$ and $8.7 \%$, for the sports hall and shopping centre respectively. Based on these values, the application of the modified ISO Equation (3) yields relevant results within the stated validity limits and is acceptable.

However, outside the valid range the difference of the modified ISO equation results and simulation results increase significantly, to almost $40 \%$ for the shopping centre, and its use is not recommended. Above the validity limits, it is necessary to employ a more detailed evaluation method which takes into account the effect of flames projecting into the smoke layer.

Figure 2 and Figure 3 also confirm that the differences between results from Equation (1) and Equation (3) (subfigures b) and c) are negligible, less than $3 \%$, which confirms that Equation (3) was derived correctly.

Due to the to the fact that Equation (3) and Equation (4) are practically identical, it is expected that the above results and limitations established for the application of Equation (3) would be the same for Equation (4), as well.

\section{Conclusions}

The paper describes a newly developed method for determining the available safe evacuation time (ASET). The calculation method was derived by modifying the ISO 16735 calculation procedure for enclosure smoke filling and implementation of the latest research results. To assess the validity of the proposed calculation method, a comparison was made with the CFAST zone model for a wide range of enclosure geometries and two types of building occupancy - sports hall (low fire load and fire growth) and shopping centre (high fire load and fire growth).

The proposed calculation method has been shown to produce results correlating well with the zone fire model simulation results. Within the identified ranges of validity, the results are of a comparable accuracy when compared to simulation results, 
meaning that the proposed simple calculation method may be used when establishing ASET from the national fire safety design parameters for the given occupancy types.

It may be concluded that this initial investigation into the utility of the proposed calculation methods yielded positive results, established the range of their validity, and identified areas for their further refinement.

\section{Acknowledgements}

This work was supported by the Ministry of the Interior of the Czech Republic, project no VI20162019034 "Research and development of established models of fire and evacuation of persons and their practical application to assessment of fire safety of buildings".

\section{References}

[1] HOSSER, D.: Manual of Fire Protection Engineering Methods [online]. Braunschweig: Technisch-Wissenschaftlicher Beirat (TWB) der Vereinigung zur Forderung des Deutschen Brandschutzes e.V. (vfdb), Technical Report TB 04/01., 3. revised and completed edition, p. 419, 2013. Available: http://www.kd-brandschutz.de/files/downloads/Leitfaden2013.pdf.

[2] TOMASKOVA, M.: Evacuation of Persons Using Fire Lifts in the Case of Fire. Svetrada, 13(6), 550-558, 2016.

[3] MRACKOVA, E.: Complex Services in the Area of Safety Systems for Persons and Property Protection. Delta, 5, p. 32, 2009.

[4] MOZER, V., POKORNY, J., KUCERA, P., VRABLOVA, L., WILKINSON, P.: Evacuation of Persons from Selected Departments in High-Rise Buildings of Healthcare Facilities. Communications - Scientific Letters of the University of Zilina, 17(4), 67-72, 2015.

[5] BS 7974:2001 Application of Fire Safety Engineering Principles to the Design of Buildings. Code of Practice. British Standards Institution, London, 2001.

[6] BENESOVA, S., BRADACOVA, I., JAGER, T.: Utility of Computer Modelling in Determination of Safe Available Evacuation Time. Communications - Scientific Letters of the University of Zilina, 18(1), 117-122, 2016.

[7] CSN P CEN/TR 12101-5 Smoke and Heat Control Systems - Part 5: Guidelines on Functional Recommendations and Calculation Methods for Smoke and Heat Exhaust Ventilation Systems. Office for Technical Standardisation, Metrology and State Testing, Prague, 2008.

[8] ISO16735 Fire safety engineering - Requirements Governing Algebraic Equations - Smoke Layers. International Organization for Standardization, Geneva, p. 55, 2006.

[9] NFPA 92 B Standard for Smoke Management Systems in Malls, Atria and Large Spaces. National Fire Protection Association, Maryland, p. 57, 2009.

[10] CSN EN 1991-1-2 Eurocode. Czech standardisation institute, Prague, p. 56, 2004.

[11] HESKESTAD, G.: Fire Plumes, Flame Height, and Air Entrainment. SFPE handbook of fire protection engineering, 4th ed., Section two, Fire Dynamic, Chapter 2-1. Society of Fire Protection Engineers, Bethesda, Md., 2008.

[12] KARLSSON, B., QUINTIERE, G. J.: Enclosure Fire Dynamics. CRC Press, Boca Raton, FL, p. 315, 2000.

[13] POKORNY, J.: Fire Plume Characteristics in the Context of Czech National Standards for Building Fire Safety Assessment. Habilitation thesis, Faculty of Safety Engineering, VSB - Technical University of Ostrava, Ostrava, p. 170, 2017.

[14] BLECHARZ, P., STVERKOVA, H.: Assessing the Service Quality in Small and Medium-Sized Companies. Actual Problems of Economics, 154(4), 206-217, 2014.

[15] CSN 730802 Fire Protection of Buildings - Non-Industrial Buildings. Office for Technical Standardisation, Metrology and State Testing, Prague, p. 122, 2009.

[16] CSN 730804 Fire Protection of Buildings - Industrial Buildings. Office for Technical Standardisation, Metrology and State Testing, Prague, p. 155, 2010.

[17] PEACOCK, R. D., RENEKE, P. A., FORNEY, G. P.: CFAST - Consolidated Model of Fire Growth and Smoke Transport (Version 7) Volume 1: Technical Reference Guide [online]. National Institute of Standards and Technology, Gaithersburg, 2017. Available: http://dx.doi.org/10.6028/NIST.TN.1889v1 [accessed 2017-02-25].

[18] PEACOCK, R. D., RENEKE, P. A., FORNEY, G. P.: CFAST, Fire Growth and Smoke Transport Modelling [online]. Available: https://www.nist.gov/el/fire-research-division-73300/product-services/consolidated-fire-and-smoke-transport-model-cfast [accessed 2017-08-18].

[19] MAYFIELD, C., HOPKIN, D.: Design Fires for Use in Fire Safety Engineering. IHS BRE Press, BRE Trust, Bracknell, 2011.

[20] SFPE Handbook of Fire Protection Engineering. 4th ed., DINENNO, P. J. (Ed.). Society of Fire Protection Engineers, National Fire Protection Association, Bethesda, Md, Mass., 2008.

[21] MARTINKA, J., HRONCOVA, E., CHREBET, T., BALOG, K.: The Influence of Spruce Wood Heat Treatment on Its Thermal Stability and Burning Process. European Journal of Wood and Wood Products, 72(4), 477-486, 2014. 